\title{
Verrucous carcinoma arising in an extended giant condyloma acuminatum (Buschke-Löwenstein tumor): a case report and review of the literature
}

\author{
Mustapha Ahsaini ${ }^{1 *}$, Yasser Tahiri ${ }^{1}$, Mohammed Fadl Tazi ${ }^{1}$, Jallaledine Elammari ${ }^{1}$, Soufiane Mellas ${ }^{1}$, \\ Abdelhak Khallouk ${ }^{1}$, Mohammed Jamal El Fassi ${ }^{1}$, My Hassan Farih' ${ }^{1}$, Hind Elfatmi ${ }^{2}$, Afaf Amarti $^{2}$ \\ and Roos E Stuurman-Wieringa ${ }^{3}$
}

\begin{abstract}
Introduction: Verrucous carcinoma of the external genitalia and perianal region is a rare variant of well-differentiated squamous cell carcinoma. It has been reported to have limited metastatic potential.

Case presentation: We report the case of a 54 year-old Moroccan man who presented with locally advanced giant condyloma acuminatum (Buschke-Löwenstein tumor) after prolonged intervals of neglect (approximately 10 years). The disease covered his suprapubic, external genitalia and perianal region. It was locally aggressive with extensive tissue destruction. After a biopsy of the lesion, the diagnosis of verrucous carcinoma was confirmed. He initially received chemoradiotherapy, followed by extensive local excision, but he developed septic shock and died a few days later.
\end{abstract}

Conclusions: The purpose of this case report is to present a case of verrucous carcinoma arising in an extensive giant condyloma acuminatum (Buschke-Löwenstein tumor) and discuss the literature on its diagnosis and management.

Keywords: Buschke-Löwenstein tumor, Chemoradiotherapy, Condyloma acuminatum, Human papillomavirus, Verrucous carcinoma

\section{Introduction}

Verrucous carcinoma (VC) was first described as a distinct well-differentiated variety of squamous cell carcinoma (SCC) by Ackerman [1]. VC tends to appear mainly in oropharynx, genitalia and soles of the feet, although it may occur anywhere on the skin. Thus, VC has been known by several different names in relation to the anatomical site of the lesion. Different treatment modalities are described for patients with VC [2,3]. Buschke-Löwenstein tumor (BLT), or giant condyloma acuminatum (GCA), was first described by Buschke and Löwenstein in 1925 [4]. It is a rare sexually transmitted disease; the incidence is estimated to be $0.1 \%$ in the general population. It is characterized by invasive growth and recurrence after treatment, and malignant transformation is possible. VC resembles BLT in clinical appearance and histology. BLT is generally considered to be VC in genital regions, although there is still some

\footnotetext{
* Correspondence: drahsaini@gmail.com

'Department of Urology, University Hospital Center Hassan II, 30000 Fez, Morocco Full list of author information is available at the end of the article
}

confusion between BLT and VC; in some reports the lesions are regarded as distinct entities [5,6]. Moreover, the human papillomavirus (HPV) positivity rate in VC is lower than in common GCA $[7,8]$. To date, these questions remain unsolved, and several investigators have attempted to elucidate the etiology.

To the best of our knowledge, this is the first case report in which a history of BLT is complicated by malignant transformation covering a large part of the patient's lower body. We present a recent systematic literature review regarding the clinical presentation and treatment of this rare tumor.

\section{Case presentation}

A 54-year-old heterosexual married Moroccan man presented with a previous uncomplicated medical history. He did not report any risk factors for human immunodeficiency virus infection (HIV). He was seen in our emergency department with a foul smelling, exquisitely tender mass arising in his suprapubic, external genitalia and perianal

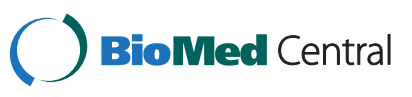


region that extended laterally to both thighs (Figure 1). This lesion had been present for 10 years and had grown slowly over time. It had been increasing in size over the previous 8 months causing pain and bleeding. His delay was due to a hospital and needle phobia. A clinical examination revealed an extensive erosive, cauliflower-like growth involving a large part of his lower body $(42 \times 31 \mathrm{~cm}$ in diameter; Figure 2). No inguinal or supraclavicular lymphadenopathy was detected clinically. He was admitted to the emergency room where multiple abscesses were drained and deep biopsies were taken from his tumor. The histological examination revealed a verrucous architecture with papillomatosis, acanthosis and a minimal loss of epithelial cell polarity (Figures 3 and 4). This confirmed the diagnosis of $\mathrm{VC}$.

Additional radiological investigations consisted of a thoracic-abdominal-pelvic computed tomography scan (Figures 5 and 6) which showed the localization of this tumor in the external genitalia, perineal and suprapubic region without any lymph nodes or distant metastases. The results of biochemical and serological investigations including a HIV test were normal. After discussion among the oncologist, radiotherapist, pathologist and surgeon, the patient was advised to undergo chemoradiation initially with the aim to reduce the size of his tumor followed by surgery.

After treatment of a local infection, our patient received two cycles of intravenous chemotherapy given three weekly with cisplatin $80 \mathrm{mg} / \mathrm{m}^{2}$ on day one and 5-fluorouracil (5FU) $600 \mathrm{mg} / \mathrm{m}^{2}$ on day one to five given as a continuous infusion. After two cycles of chemotherapy the tumor size was reduced to $30 \%$ of initial size. The radiation was planned in two phases, two total doses of 45Gy in 25 fractions over 5 weeks, given at $1.8 \mathrm{~Gy}$ per fraction. The combined therapy was well tolerated with just diarrhea as a side effect. Six months after completing the treatment, he

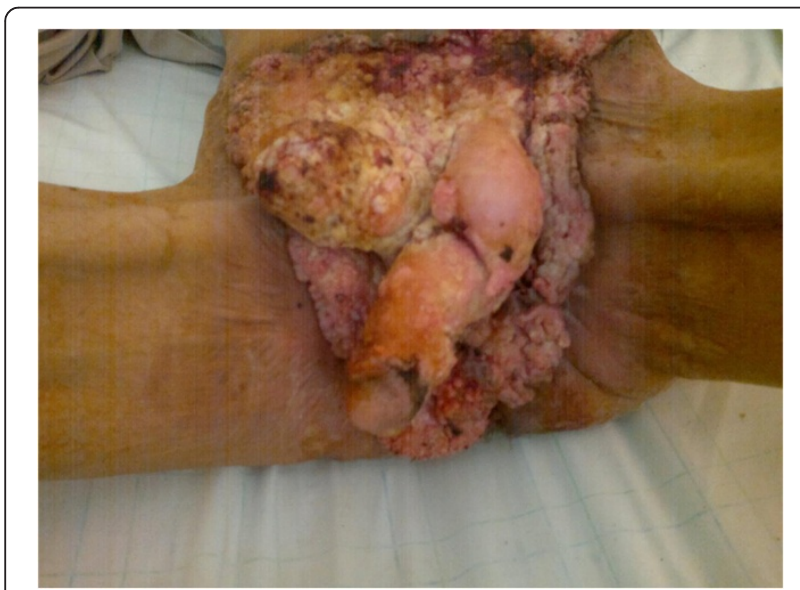

Figure 1 The tumor arising from the suprapubic, external genitalia and perianal region extended laterally to both thighs.

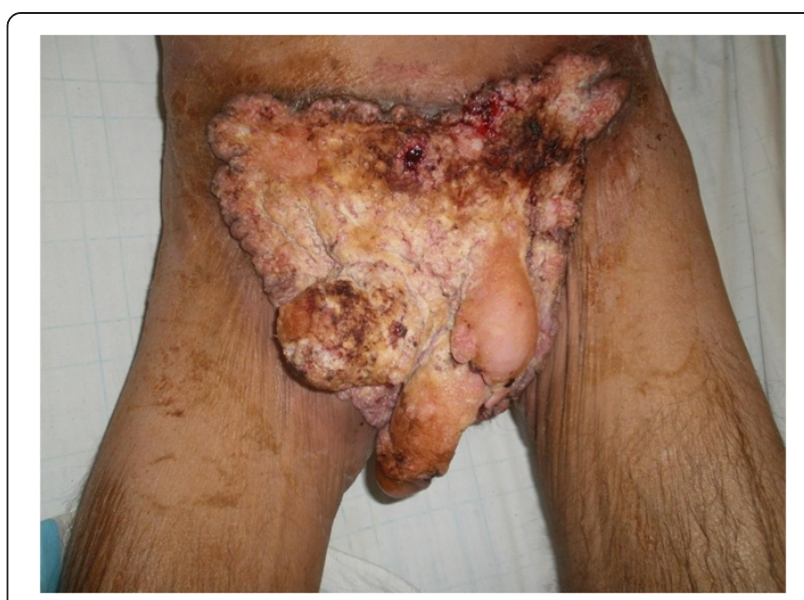

Figure 2 An extensive erosive, cauliflower-like growth involving a large part of the lower body.

underwent local excision with extensive abdominoperineal rectum excision and emasculation. In addition, a temporary diverting colostomy and a bilateral ureterostomy were constructed. Pedicled anterolateral thigh flaps and abdominal flap were used to cover the perineal defects. Unfortunately he developed septic shock and died some days later. The final pathology report after surgical resection of the tissue confirmed the diagnosis of $\mathrm{VC}$.

\section{Discussion}

BLT is a rare sexually transmitted disease triggered by HPV, usually genotype 6 or 11 [4]. Risk factors for HPV transmission are: multiple sexual partners, prostitution, homosexuality, lack of hygiene, and chronic genital infections. BLT is always preceded by condyloma acuminatum and the immune system is probably suppressed. It can be associated with congenital or acquired immunodeficiency,

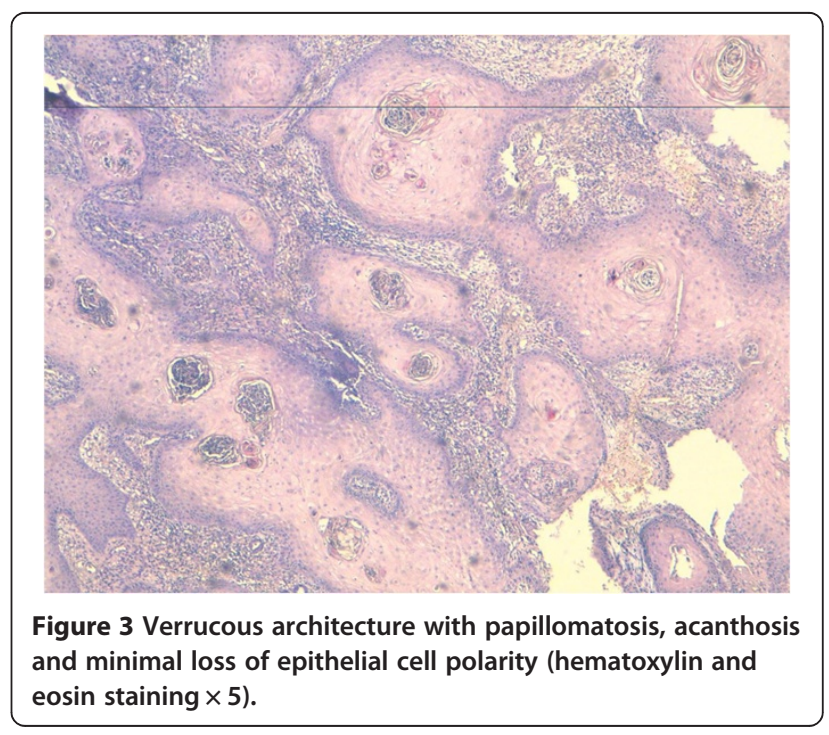




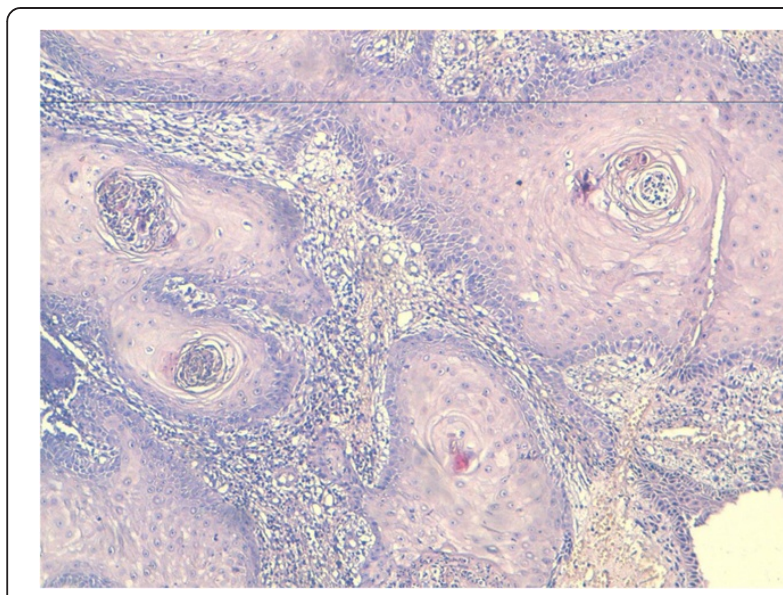

Figure 4 Koilocytosis and cellular binucleation (hematoxylin and eosin staining $\times 10$ ).

alcoholism, diabetes, or chemotherapy with immunosuppressive therapy [9]. Our patient did not have any of these risk factors. Other oncogenic subtypes, particularly HPV $16,18,31$, and 33 , have a well-known association with anogenital SCC [10]. Moreover, it is believed that malignant transformation could also be caused by the release of free oxygen radicals by activated inflammatory cells, inducing genetic damage and neoplastic transformation $[11,12]$.

The absence of high-risk HPV subtypes in a case of BLT cannot exclude focally invasive SCC. Histopathological criteria for malignancy and clinical presentation continue to lead management decisions [5,6]. The average time for malignant transformation is known to be

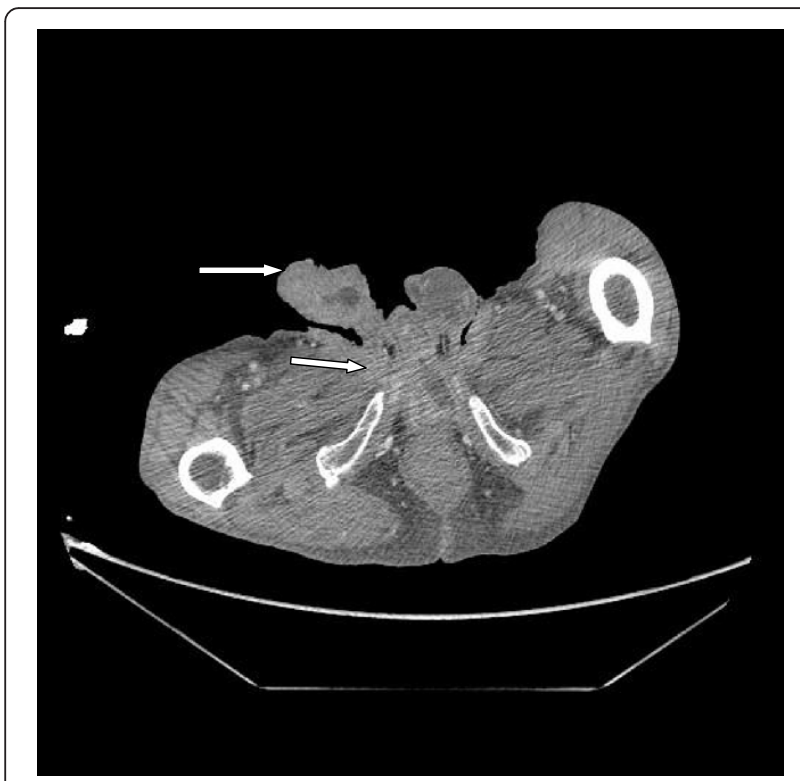

Figure 5 Computed tomography of the perineum showing the tumor spreading into the perineum and base of the scrotum (white arrows).

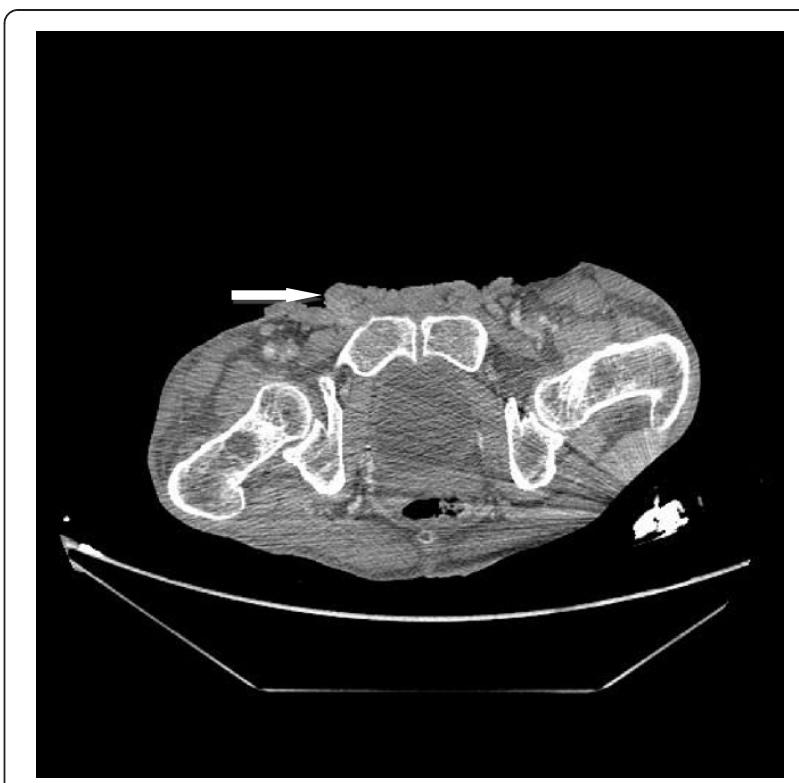

Figure 6 Computed tomography of the abdominal-pelvic floor showing the tumor invading the suprapubic region (white arrow).

approximately 5 years [12]. Our patient had the tumor for approximately 10 years. The mean age of patients with BLT is 43 years, with a male to female ratio of $2: 2$. The risk of recurrence after excision is 60 to $66 \%$, with an overall mortality of 20 to $30 \%$. Malignant transformation has been reported in 30 to $56 \%$ of cases [12-14].

The disease is located on the penis in 81 to $94 \%$ of cases, in the anorectal area in 10 to $17 \%$, and in the urethra in $5 \%$. In females, the location is chiefly the vulva (90\%) and an anorectal location is less frequent [15]. Suprapubic localization is rarely reported in the literature [16]. Our patient presented with an extensive lesion involving his suprapubic, external genitalia and perianal region that extended laterally to both thighs which is rarely reported in the literature.

Clinically, the tumor presents as exophytic fungating masses, sometimes with a cauliflower-like morphology. The gross appearance is generally a bulky tumor suggesting an aggressive behavior, whereas histopathology reveals a relatively low-grade malignancy. Biologically, this tumor shows a high recurrence rate and it is characterized by a low incidence of metastasis $[17,18]$. Malignant transformation may be suspected when bleeding, pain, and a rapid increase in tumor size [19] appears. Our patient had these complications in the last 8 months suggesting the malignant transformation was probably due to the time delay.

The diagnosis of $\mathrm{VC}$ requires evaluation of the clinical and microscopic appearance and biologic behavior of the neoplasm [20]. It is important to perform deep skin biopsies when clinical suggestion of VC exists.

$\mathrm{VC}$ presents as a distinct entity with an exo-endophytic growth pattern (in contrast to condyloma accuminata) of 
squamous cells showing mild atypia with pushing margins (in contrast to the invasive character of well-differentiated squamous carcinoma). This results in slow-growing lesions, locally invasive behavior, and very infrequent metastatic spread [11].

Differentiation between BLT and VC is difficult. Some authors consider these lesions to be similar. However, others maintain that BLT represents an intermediate lesion between condyloma acuminatum and $\mathrm{VC}$, referring to it as a condyloma-like precancerous lesion [9].

Wide surgical excision, chemoradiation, topical and intralesional chemotherapy, carbon dioxide laser therapy, and photodynamic therapy have all been used in different combinations in the treatment of BLT, with varying success. Surgery is the treatment of choice and is effective in the early stages of the disease. Excision must be wide, and ranges from the Mohs technique when the size of the tumor is small, to abdominoperineal excision with pelvic lymph node dissection if lymph metastasis was suspected $[14,21]$.

Radiotherapy alone is rarely used; it is usually used alone when excision cannot be performed or in recurrences. It may also be indicated to complement surgery in the case of an incomplete excision [14,21]. In addition, radiotherapy is controversial because of the potential for malignant transformation into aplastic carcinoma and metastasis [22].

Chemotherapy consists of a combination of cisplatin and 5-FU. The choice of this protocol was based on our own experience in treatment of patients with anal cancer. This combination has been used combined with radiation with acceptable toxicity and positives responses [23]. In patients with BLT with suspicion of malignant transformation, the optimal treatment is not well defined. Some authors recommend preoperative chemoradiotherapy to downstage extensive tumors, followed by radical surgery [24]. Tytherleigh et al. [25] reported the case of a patient with unresectable disease who received neoadjuvant chemoradiotherapy to downsize a tumor with subsequent complete surgical excision. In our patient, chemoradiotherapy allowed us to downsize the tumor (30\%); wide excision of the tumor was made possible. However, due to this extensive procedure associated with significant morbidity and mortality, our patient died from septic shock despite extensive antibiotic treatment.

To avoid the recurrent disease some authors suggest the administration of an autogenous vaccine after surgical excision. The lowest reported recurrence rate at 1 year was less than $5 \%$ [26].

\section{Conclusions}

$\mathrm{VC}$ is a rare, locally aggressive tumor. Surgical complete excision of $\mathrm{VC}$ is advised. Other treatment modalities such as chemotherapy or radiotherapy could be used to avoid mutilating surgical interventions. Based on our case and other published reports, chemoradiotherapy should be considered in patients with malignant transformation of GCA to downsize the tumor. Decision making in regarding to the goals of surgical intervention is complex and involves palliative excision versus a curative excision which unfortunately has the potential of significant morbidity and mortality. Wide surgical excision with local flap reconstruction can significantly improve the quality of life. A regular follow-up is necessary due to frequent recurrences and possible distant metastasis.

\section{Consent}

Written informed consent was obtained from the patient's next-of-kin for publication of this case report and any accompanying images. A copy of the written consent is available for review by the Editor-in-Chief of this journal.

\section{Competing interests}

The authors declare that they have no competing interests.

\section{Authors' contributions}

MA was the principal author and major contributor in writing the manuscript. YT, MFT, SM, JE, AK, and HE analyzed and interpreted the patient data and reviewed the literature. RSW, MJE, MHF, and AA read and corrected the manuscript. All authors read and approved the final manuscript.

\section{Author details}

${ }^{1}$ Department of Urology, University Hospital Center Hassan II, 30000 Fez, Morocco. ${ }^{2}$ Department of Pathology, University Hospital Center Hassan II, Fez, Morocco. ${ }^{3}$ Department of Urology, Reinier de Graaf Gasthuis, P.O. box 5011, 2600, GA Delft, The Netherlands.

Received: 21 April 2013 Accepted: 28 October 2013

Published: 19 December 2013

\section{References}

1. Ackerman LV: Verrucous carcinoma of the oral cavity. Surgery 1948 23:670-678.

2. Trombetta LJ, Place RJ: Giant condyloma acuminatum of the anorectum trends in epidemiology and management: report of a case and review of the literature. Dis Colon Rectum 2001, 44:1878-1886.

3. Dogan G, Oram Y, Hazneci E, Ozen S, Karincaoglu Y, Ciralik H: Three cases of verrucous carcinoma. Australas J Dermatol 1998, 39:251-254.

4. Buschke A, Löwenstein L: Über carcinomähnliche condylomata accuminata des Penis. Klin Wochenschr 1925, 4:1726-1728.

5. Masih AS, Stoler MH, Farrow GM, Wooldridge TN, Johansson SL: Penile verrucous carcinoma: a clinicopathologic, human papillomavirus typing and flow cytometric analysis. Mod Pathol 1992, 5:48-55.

6. Pilotti S, Donghi R, D'Amato L: HPV detection and p53 alteration in squamous cell verrucous malignancies of the lower genital tract. Diagn Mol Pathol 1993, 2:248-256.

7. Cupp MR, Malek RS, Goellner JR, Smith TF, Espy MJ: The detection of human papillomavirus deoxyribonucleic acid in intraepithelial, in situ, verrucous and invasive carcinoma of the penis. J Urol 1995, 154:1024-1029.

8. Dianzani C, Bucci M, Pierangeli A, Calvieri S, Degener M: Association of human papilloma virus type 11 with carcinoma of the penis. Urology 1998, 51:1046-1048.

9. Gillard P, Vanhooteghem O, Richert B, De La Brasine M: Tumor de Buschke-Loewenstein. Ann Dermatol Venereol 2005, 132:98-99.

10. Majewski S, Jablonska S: Human papillomavirus-associated tumors of the skin and mucosa. J Am Acad Dermatol 1997, 36(5 Pt 1):659-685.

11. Geusau A, Heinz-Peer G, Volc-Platzer B, Stingl G, Kirnbauer R: Regression of deeply infiltrating giant condyloma (Buschke-Löwenstein tumor) following long-term intralesional interferon alfa therapy. Arch Dermatol 2000, 136:707-710. 
12. Chu QD, Vereridis MP, Libbey NP, Wanebo HJ: Giant condyloma acuminatum (Buschke Lowenstein tumor) of the anorectal and perianal regions. Dis Colon Rectum 1994, 37:950-957.

13. Creasman C, Haas PA, Fox TA, Balazs M: Malignant transformation of anorectal giant condyloma acuminatum (Buschke Lowenstein tumor). Dis Colon Rectum 1989, 32:481-487.

14. Bertram P, Treutner KH, Rubben A, Hauptmann S, Schumpelick V: Invasive squamous cell carcinoma in giant anorectal condyloma (Buschke Lowenstein tumor). Langenbecks Arch Chir 1995, 380:115-118.

15. El Mejjad A, Amine El M, Mohamed D, Mohamed T, Hichame A, Abdeltif C, Ahmed A, Rachid A, Fethi M: Le condylome acuminé géant-tumeur de Buschke Loewenstein (à propos de 3 cas). Prog Urol 2003, 13(3):513-517.

16. Blake PA, Kim CO, Lopez AE, Krongrad A: Verrucous carcinoma of a suprapubic cystostomy track. J Urol 1996, 156:174.

17. Levy A, Lebbe C: Buschke-Lowenstein tumor: diagnosis and treatment. Ann Urol (Paris) 2006, 40:175-178.

18. Chao MW, Gibbs P: Squamous cell carcinoma arising in a giant condyloma acuminatum (Buschke-Lowenstein tumor). Asian J Surg 2005, 28:238-240.

19. Merzouk M, Moumen M, Biadillah MCH: Tumeur de Buschke Löwenstein de localisation ano-perianale dégénérée: a propose de 2 cas. Médecine du Maghreb 1992, 35:21-22.

20. Sheen MC, Sheu HM, Chai CY, Huang CH, Chuang JH, Lin TM, Wang YW: Clinical and histological effects of aortic infusion of methotrexate for penile squamous cell carcinoma. Reg Cancer Treat 1994, 7:27-32.

21. Qarro A, Ait Ali A, Choho A, Alkandry S, Borki K: Tumeur de Buschke Loewenstein à localisation anorectale (à propos de trois cas). Ann Chir 2005, 130:96-100.

22. Fukunaga M, Yokoi K, Miyazawa Y, Harada T, Ushigome S: Penile verrucous carcinoma anaplastic transformation following radiotherapy: a case report with human papillomavirus typing and flow cytometric DNA studies. Am J Surg Pathol 1994, 18:501.

23. Munro A: UKCCCR Anal cancer ACT II Trial. BJC 2000, 83 Suppl 1(S17):7.

24. Elliot MS, Werner ID, Immelman EJ, Harrison AC: Giant condyloma of the anorectum. Dis Colon Rectum 1979, 22:497-500

25. Tytherleigh MG, Birtle AJ, Cohen CE, Glynne-Jones R, Livingstone J, Gilbert J: Combined surgery and chemoradiation as a treatment for the Buschke-Löwenstein tumour. Surgeon 2006, 4:378-383.

26. Wiltz $\mathrm{OH}$, Torregrosa $\mathrm{M}$, Wiltz $\mathrm{O}$ : Autogenous vaccine: the best therapy for perianal condyloma acuminata? Dis Colon Rectum 1995, 38:838-841.

doi:10.1186/1752-1947-7-273

Cite this article as: Ahsaini et al.: Verrucous carcinoma arising in an extended giant condyloma acuminatum (Buschke-Löwenstein tumor): a case report and review of the literature. Journal of Medical Case Reports 2013 7:273

\section{Submit your next manuscript to BioMed Central and take full advantage of:}

- Convenient online submission

- Thorough peer review

- No space constraints or color figure charges

- Immediate publication on acceptance

- Inclusion in PubMed, CAS, Scopus and Google Scholar

- Research which is freely available for redistribution 